Part of Journal of Research of the National Bureau of Standards, Volume 20, January 1938

\title{
CRITICAL SOLUTION TEMPERATURES OF MIXTURES OF GASOLINE, $n$-PROPYL ALCOHOL, AND WATER
}

\author{
By Elizabeth W. Aldrich
}

\section{ABSTRACT}

Data are presented on the separation temperatures of mixtures of $5,10,15,20$, and 25 percent of $n$-propyl alcohol of various water contents with each of three gasolines. These data are compared with similar data on mixtures of gasoline with ethyl alcohol, and it is shown that the water tolerances of mixtures of gasoline with $n$-propyl alcohol are, in general, greater than those of corresponding mixtures with ethyl alcohol.

\section{CONTENTS}

Page

I. Introduction

II. Preparation of $n$-propyl alcohol solutions_...... 9

III. Experimental procedure.....

IV. Experimental data

V. Conclusion

VI. References_...

\section{INTRODUCTION}

Previous papers $[1,2,3,4]^{1}$ on the solubility of ethyl alcohol in gasoline have shown that mixtures of gasoline with ethyl alcohol have only a small water tolerance. Therefore, only very small percentages of water may be present in such mixtures if separation into two liquid phases is to be avoided. This is a technical difficulty in the use of mixtures of gasoline with ethyl alcohol as motor fuels, since it is necessary to use alcohol almost free from water in preparing the blend and to protect the mixed fuel from water or to add a blending agent to increase the water tolerance.

Since the solubility of methyl alcohol solutions in gasoline is less than that of ethyl alcohol solutions containing the same amount of water, it seemed probable that the solubility of the aqueous aliphatic alcohols in gasoline might increase with molecular weight. Therefore, an investigation was undertaken of the solubility of aqueous solutions of some of the higher aliphatic alcohols. The present paper deals with the solubility in gasolines of $n$-propyl alcohol containing various amounts of water in gasolines as indicated by the temperature of separation into two phases in solutions of known compositions.

\section{PREPARATION OF n-PROPYL ALCOHOL SOLUTIONS}

The $n$-propyl alcohol used in these experiments was a commercial refined product and was used without further purification. The

1 Figures in brackets here and elsewhere in the text correspond to the numbered references at the end of this paper. 
density of the alcohol was 0.79668 at $30^{\circ} \mathrm{C}$ and its boiling range was from 96.2 to $97.2^{\circ} \mathrm{C}$. The comparatively narrow boiling range and the density, which corresponds to an aqueous solution containing 99.67 weight percent of $n$-propyl alcohol, indicate that the alcohol contained only a small amount of impurities.

Treatment of the commercial product with calcium oxide reduced the density at $30^{\circ} \mathrm{C}$ to 0.79605 , which corresponds to an aqueous solution of $n$-propyl alcohol containing 99.91 weight percent of alcohol, and also reduced the boiling range, which became 97.2 to $97.4^{\circ} \mathrm{C}$. These changes in properties on drying indicated that practically all of the impurity was water. For the present work, it was assumed that no other impurity was contained in the alcohol in sufficient quantities to affect the densities of its aqueous solutions, and the compositions of the $n$-propyl alcohol solutions used were calculated from density determinations.

Eight $n$-propyl alcohol solutions containing approximately 1 to 8 volume percent of water were prepared. The density at $30^{\circ} \mathrm{C}$ of each of these was determined by use of calibrated picnometers of the Osborne [5] type of approximately 21-ml capacity. From the densities the compositions in weight percentage were obtained using the table in the International Critical Tables [6], which gives the composition in weight percentage corresponding to various densities at several temperatures, including $30^{\circ} \mathrm{C}$. The alcohol concentrations in volume percentage at $60^{\circ} \mathrm{F}$ were then calculated using values of the densities of the $n$-propyl alcohol solutions at $60^{\circ} \mathrm{F}$ and of pure $n$-propyl alcohol at $60^{\circ} \mathrm{F}$. It was necessary to obtain these density values at $60^{\circ} \mathrm{F}$ by interpolation from the values in the International Critical Tables at 0,15 , and $30^{\circ} \mathrm{C}$. A further calculation was made to determine the volume percentage of water in each solution. Volume percentage as here used is equal to the volume in milliliters at $60^{\circ} \mathrm{F}$ of pure $n$ propyl alcohol and of pure water, respectively, which were mixed to make $100 \mathrm{ml}$ of solution at $60^{\circ} \mathrm{F}$. Since there is a contraction in volume on mixing $n$-propyl alcohol and water, the sum of the volume percentages of the two constituents exceeds 100 .

After completion of measurements of separation temperatures of mixtures with gasoline, density determinations were made again on the eight stock $n$-propyl alcohol solutions to check the concentrations and to determine whether any changes due to water absorption had occurred. No changes of more than 1 part in 2,000 were observed.

In the course of the work, the preparation of additional $n$-propyl alcohol solutions was found desirable. These solutions were prepared by mixing weighed amounts of two of the eight original $n$-propyl alcohol solutions or by adding a weighed amount of water to a weighed amount of one of the $n$-propyl alcohol solutions.

\section{EXPERIMENTAL PROCEDURE}

The method of preparing the mixtures of gasoline with alcohol and the apparatus and procedure used in determining the separation temperatures are described in a previous paper [1].

Three gasolines were used in the present work and identification data on each are given in table 1. 
TABLE 1.-Identification data on gasolines

\begin{tabular}{|c|c|c|c|c|c|}
\hline \multirow{2}{*}{ Sample } & \multirow{2}{*}{ Description } & \multicolumn{4}{|c|}{$\begin{array}{c}\text { Distillation temperatures at stated percentages } \\
\text { evaporated, }{ }^{\circ} \mathrm{C} .\end{array}$} \\
\hline & & $\begin{array}{c}10 \\
\text { percent }\end{array}$ & $\begin{array}{c}50 \\
\text { percent }\end{array}$ & $\begin{array}{c}90 \\
\text { percent }\end{array}$ & $\begin{array}{l}\text { Specific } \\
\text { gravity } \\
60^{\circ} / 60^{\circ}\end{array}$ \\
\hline $\begin{array}{l}A \\
B \\
B\end{array}$ & $\begin{array}{l}\text { U. S. motor gasoline } \\
\text { Refinery naphtha } \\
\text { Natural gasoline }\end{array}$ & $\begin{array}{l}73 \\
76 \\
51\end{array}$ & $\begin{array}{r}121 \\
121 \\
58\end{array}$ & $\begin{array}{l}186 \\
182 \\
109\end{array}$ & $\begin{array}{r}0.758 \\
.747 \\
.683\end{array}$ \\
\hline
\end{tabular}

Critical solution temperatures of mixtures of each of these gasolines with ethyl alcohol solutions containing various percentages of water were first determined, to serve as a basis of comparison with the values obtained with $n$-propyl alcohol mixtures. The characteristic constant $K$ for each gasoline was calculated as described in a previous paper [4]. The value of $K$ for gasoline $A$ is 597, for gasoline $B$ is 628 and for gasoline $C$ is 462 . Using these values of $K$, critical solution temperatures of each of the three gasolines were computed. The agreement between observed and calculated values is shown graphically in figure 1 . The average deviation is $1.5^{\circ} \mathrm{C}\left(2.7^{\circ} \mathrm{F}\right)$.

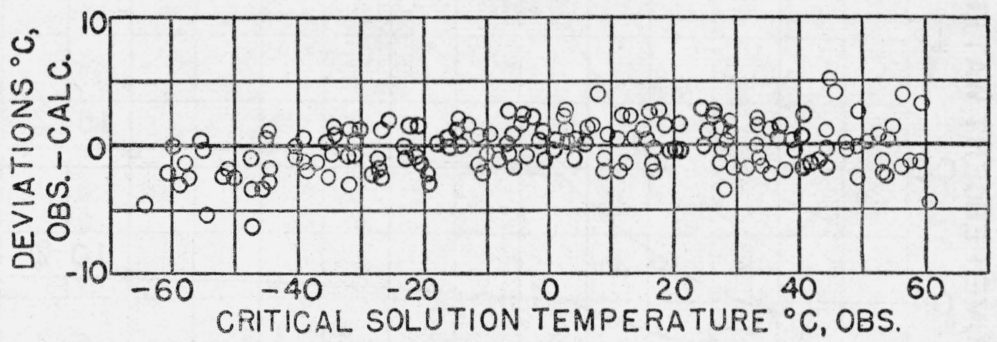

FIGURE 1.-Comparison of calculated and observed values of critical solution temperatures of mixtures of gasolines $A, B$, and $C$ with ethyl alcohol

With each gasoline, mixtures containing 5, 10, 15, 20, and 25 percent of each of the $n$-propyl alcohol solutions were prepared. The percentage referred to as volume percentage is strictly the volume of $n$-propyl alcohol solution which, when mixed with the appropriate volume of gasoline, gives a summation of volumes equal to 100 at $60^{\circ} \mathrm{F}$. Immediately after preparation the separation temperature of each mixture was determined. No measurements were made, however, unless the temperature fell between +65 and $-65^{\circ} \mathrm{C}$.

A large number of the separation temperatures obtained were freezing points rather than critical solution temperatures, as the second phase which appeared was solid crystals rather than liquid. It was also found that where a second liquid phase appeared, crystals were subsequently obtained on further cooling.

Duplicate determinations of the separation temperatures which were freezing points, agreed in most cases within $0.2^{\circ} \mathrm{C}$. On the other hand, as may be seen in figures 2,3 , and 4 , the slope of the critical-solution-temperature curves is so small that extremely minute 
differences in water content make differences of many degrees in the critical solution temperature, and accordingly, in this range the reproducibility of separation temperatures is not good. This is not of any practical importance since such errors do not change the positions of these curves.

\section{EXPERIMENTAL DATA}

The data obtained are shown graphically in figures 2, 3, and 4, where the volume percentage of water at $60^{\circ} \mathrm{F}$ in the mixture is plotted

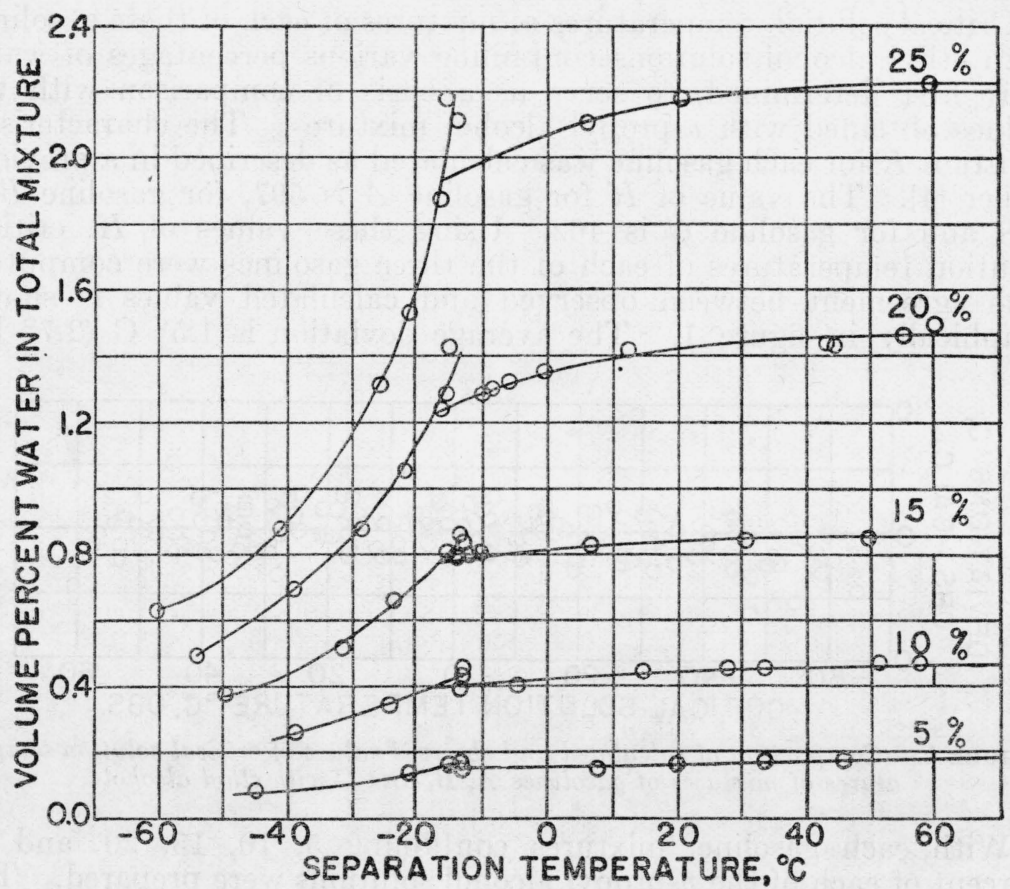

FIGURE 2.-Effect of water content on the separation temperatures of mixtures of gasoline A with aqueous n-propyl alcohol.

against the separation temperature. In these plots the curves on the left are freezing-point curves, while those on the right are criticalsolution-temperature curves. It will be noted that freezing occurs in all cases at temperatures below about $-15^{\circ} \mathrm{C}$.

The water tolerances at a number of temperatures for mixtures of each of the three gasolines with $n$-propyl alcohol are given in table 2 . These data are smoothed values read from plots of volume percentage of water in the mixture against separation temperature. Similar smoothed data for ethyl alcohol mixtures with these gasolines are included for comparison. 


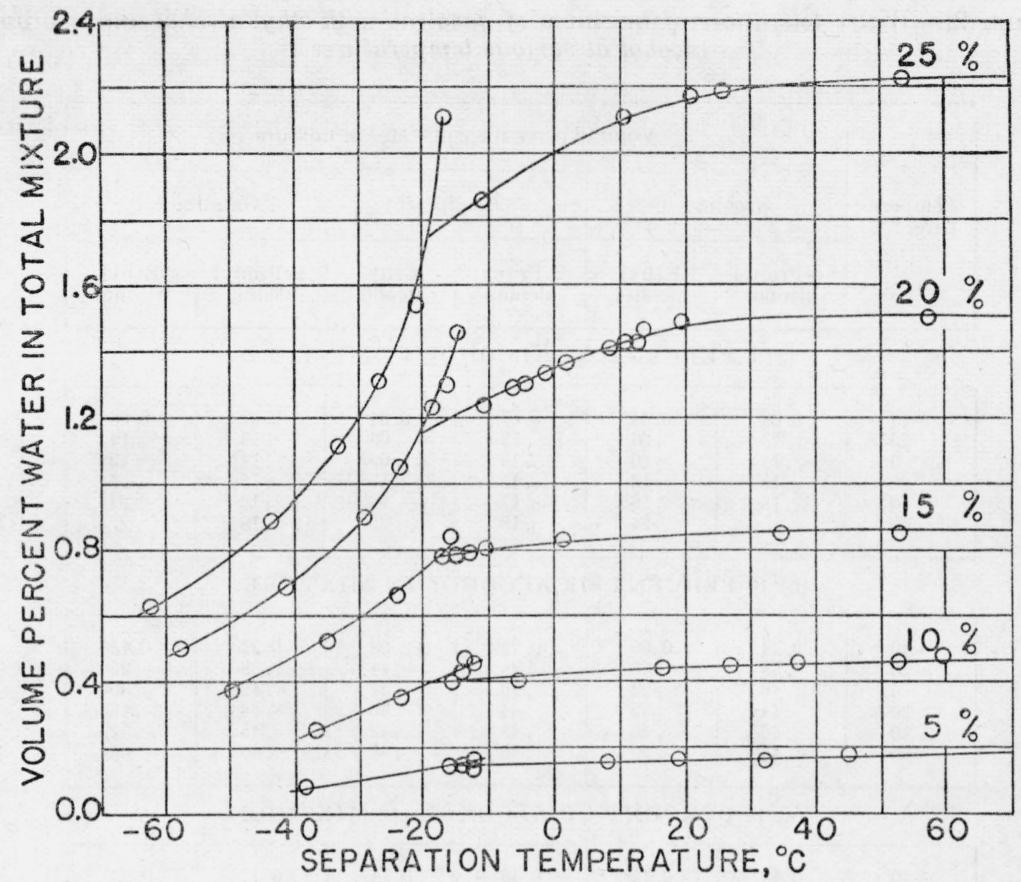

FIGURE 3.-Effect of water content on the separation temperature of mixtures of gasoline $B$ with aqueous n-propyl alcohol.

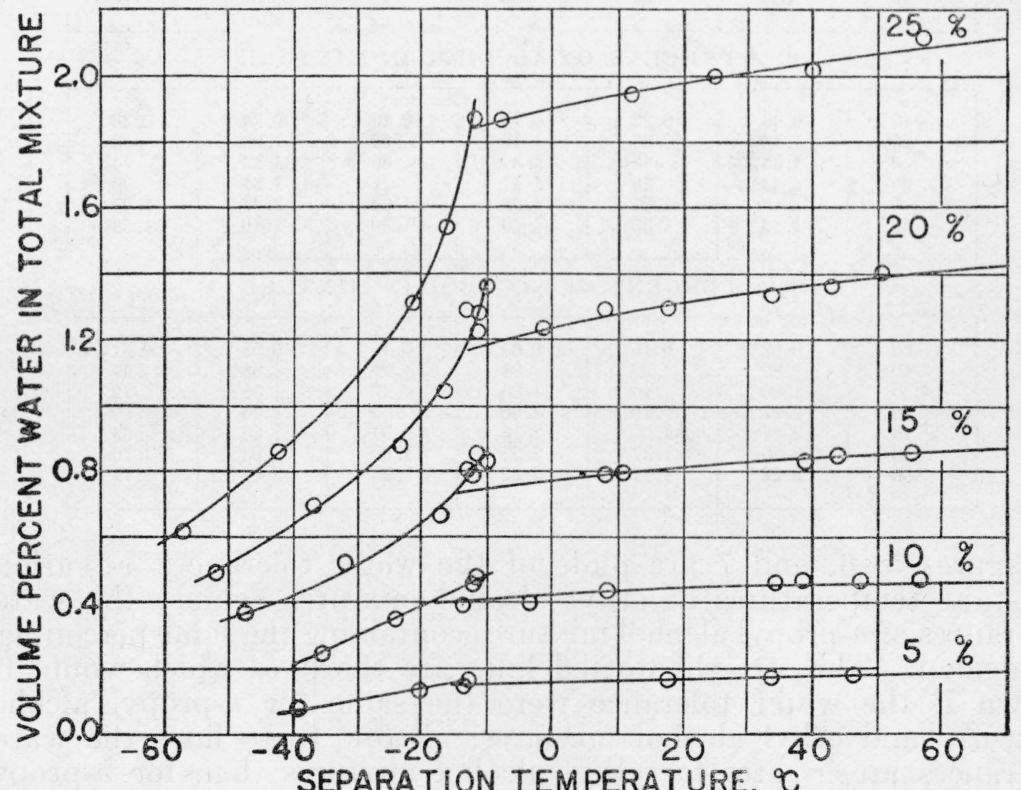

FIGURE 4.-Effect of water content on the separation temperatures of mixtures of gasoline C with n-propyl alcohol. 
TABLE 2.-Water tolerances of mixtures of gasoline with ethyl alcohol and n-propyl alcohol at various temperatures

\begin{tabular}{|c|c|c|c|c|c|c|}
\hline \multirow{3}{*}{$\begin{array}{l}\text { Tempera- } \\
\text { ture, }{ }^{\circ} \mathrm{C}\end{array}$} & \multicolumn{6}{|c|}{ Volume percentage of water in mixture } \\
\hline & \multicolumn{2}{|c|}{ Gasoline $A$} & \multicolumn{2}{|c|}{ Gasoline $B$} & \multicolumn{2}{|c|}{ Gasoline $C$} \\
\hline & $\begin{array}{l}n \text {-Propyl } \\
\text { alcohol }\end{array}$ & $\begin{array}{c}\text { Ethyl } \\
\text { alcohol }\end{array}$ & $\begin{array}{l}n \text {-Propyl } \\
\text { alcohol }\end{array}$ & $\begin{array}{c}\text { Ethyl } \\
\text { alcohol }\end{array}$ & $\begin{array}{c}n \text {-Propyl } \\
\text { alcohol }\end{array}$ & $\begin{array}{l}\text { Ethyl } \\
\text { alcohol }\end{array}$ \\
\hline
\end{tabular}

(a) 5 PERCENT OF ALCOHOL IN MIXTURE

\begin{tabular}{|r|r|r|r|r|r|r|}
\hline-40 & 0.08 & 0.04 & 0.07 & 0.04 & 0.07 & 0.06 \\
-20 & .13 & .06 & .12 & .06 & .13 & .19 \\
0 & .14 & .10 & .13 & .09 & .14 & .12 \\
20 & .15 & .13 & .15 & .13 & .15 & .17 \\
40 & .16 & .18 & .17 & .18 & .16 & .22 \\
60 & .18 & .24 & .18 & .22 \\
\hline
\end{tabular}

(b) 10 PERCENT OF ALCOHOL IN MIXTURE

\begin{tabular}{|r|r|r|r|r|r|r|}
\hline-40 & 0.24 & 0.09 & 0.22 & 0.08 & 0.21 & 0.15 \\
-20 & .38 & .15 & .38 & .14 & .38 & .22 \\
0 & .40 & .22 & .40 & .21 & .42 & .30 \\
20 & .44 & .32 & .44 & .30 & .44 & .40 \\
40 & .46 & .43 & .45 & .42 & .45 & .52 \\
60 & .46 & .55 & .46 & .55 & .46 & .65 \\
\hline
\end{tabular}

(c) 15 PERCENT OF ALCOHOL IN MIXTURE

\begin{tabular}{|r|r|r|r|r|r|r|}
\hline-40 & 0.43 & 0.15 & 0.46 & 0.14 & 0.42 & 0.25 \\
-20 & .70 & .25 & .73 & .23 & .64 & .36 \\
0 & .82 & .37 & .82 & .35 & .77 & .52 \\
20 & .84 & .53 & .84 & .50 & .81 & .69 \\
40 & .85 & .72 & .85 & .69 & .84 & .88 \\
50 & .85 & .95 & .86 & .91 & .85 & 1.10 \\
\hline
\end{tabular}

(d) 20 PERCENT OF ALCOHOL IN MIXTURE

\begin{tabular}{|r|r|r|r|r|r|r|}
\hline-40 & 0.66 & 0.22 & 0.70 & 0.19 & 0.64 & 0.36 \\
-20 & 1.10 & .35 & 1.16 & .32 & .96 & .53 \\
0 & 1.36 & .53 & 1.34 & .49 & 1.23 & .74 \\
20 & 1.43 & .76 & 1.47 & .71 & 1.31 & .99 \\
40 & 1.45 & 1.03 & 1.48 & .98 & 1.37 & 1.27 \\
60 & 1.46 & 1.35 & 1.49 & 1.30 & 1.40 & 1.58 \\
\hline
\end{tabular}

(e) 25 PERCENT OF ALCOHOL IN MIXTURE

\begin{tabular}{|r|r|r|r|r|r|r|}
\hline-60 & 0.62 & 0.16 & 0.64 & 0.14 & 0.58 & 0.31 \\
-40 & .89 & .29 & .94 & .25 & .88 & .49 \\
-20 & 1.60 & .46 & 1.66 & .42 & 1.35 & .72 \\
0 & 2.07 & .70 & 2.00 & .65 & 1.90 & 1.00 \\
20 & 2.17 & 1.00 & 2.16 & .94 & 1.98 & 1.33 \\
40 & 2.20 & 1.37 & 2.21 & 1.30 & 2.03 & 1.70 \\
60 & 2.22 & 1.71 & 2.22 & 1.73 & 2.07 & 2.11 \\
\hline
\end{tabular}

Figures 5, 6, and 7 are plots of the water tolerances at various constant temperatures of ethyl alcohol mixtures against the water tolerances of $n$-propyl alcohol mixtures containing the same percentage of alcohol. The straight dotted lines are the lines which would be drawn if the water tolerance were the same for $n$-propyl alcohol mixtures and ethyl alcohol mixtures. Below these lines the water tolerances are greater for ethyl alcohol mixtures than for $n$-propyl alcohol mixtures and above these lines the reverse is true.

It is seen that in general $n$-propyl alcohol mixtures have a greater water tolerance than ethyl alcohol mixtures. The differences in this 
direction are largest at the lower temperatures and with the higher alcohol concentrations. At the higher temperatures the water tolerances are more nearly the same and in some cases, particularly at the lower alcohol concentrations, the amount of water which may be

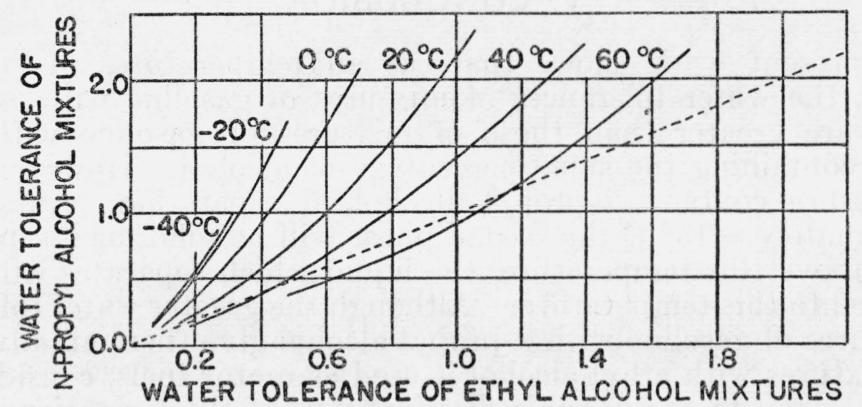

FIgURE 5.-Comparison of the water tolerances of mixtures of gasoline $A$ with ethyl alcohol and with n-propyl alcohol at various constant temperatures.

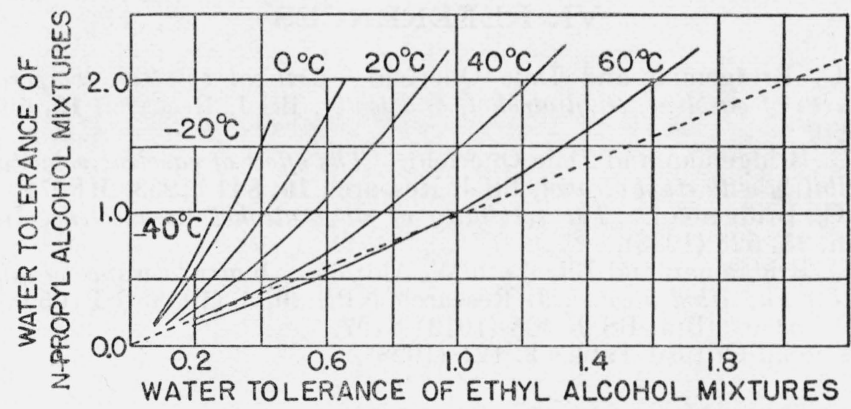

FIGURE 6.-Comparison of the water tolerances of mixtures of gasoline $B$ with ethyl alcohol and with n-propyl alcohol at various constant temperatures.

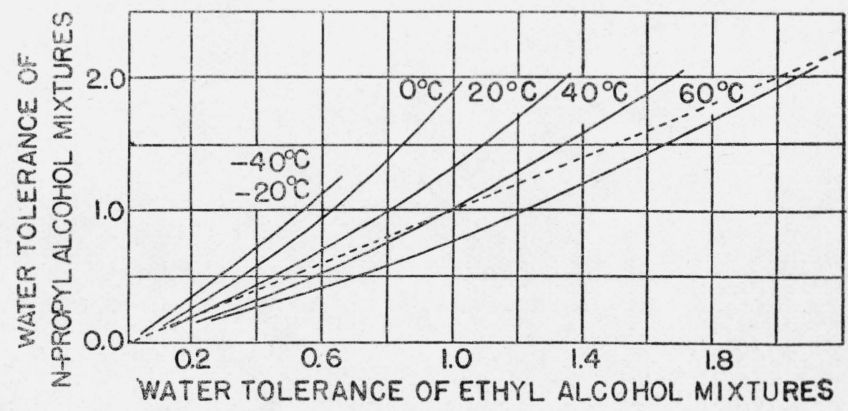

FIgURE 7.-Comparison of the water tolerances of mixtures of gasoline $C$ with ethyl alcohol and with n-propyl alcohol at various constant temperatures.

present without separation is greater if the mixture contains ethyl alcohol. However, the temperatures at which the water tolerances of ethyl alcohol mixtures are greater, are above atmospheric temperature in most cases and are therefore of no practical interest. 
It should be noted that at the temperatures $-40^{\circ}$ and $-20^{\circ} \mathrm{C}$ the material which separates is solid if the mixture contains $n$-propyl alcohol and is liquid if the mixture contains ethyl alcohol.

\section{CONCLUSION}

The present work shows that, at all temperatures of practical interest, the water tolerances of mixtures of gasoline with $n$-propyl alcohol are greater than those of mixtures of gasoline with ethyl alcohol containing the same percentage of alcohol. However, when the mixture contains $n$-propyl alcohol, if separation occurs below approximately $-15^{\circ} \mathrm{C}$ the second phase will be solid, or if separation occurs above this temperature, the liquid which separates will freeze if lowered to this temperature. Although the greater water tolerances of mixtures of gasoline with $n$-propyl alcohol give them an advantage over mixtures with ethyl alcohol if used as motor fuels, consideration must be given to the possible disadvantage of the formation of solid material which does not occur in mixtures with ethyl alcohol.

\section{REFERENCES}

[1] Oscar C. Bridgeman and Dale Querfeld. Critical solution temperatures of mixtures of gasoline, ethyl alcohol, and water, BS J. Research 10, 693 (1933) RP560.

[2] Oscar C. Bridgeman and Dale Querfeld. The effect of gasoline volatility on the miscibility with ethyl alcohol, BS J. Research 10, 841 (1933) RP571.

[3] Oscar C. Bridgeman. The solubility of ethyl alcohol in gasoline, Ind. Eng. Chem. 25, 523 (1933).

[4] Oscar C. Bridgeman and Elizabeth W. Aldrich. Water tolerance of mixtures of gasoline and ethyl alcohol, J. Research NBS \%0, 1 (1938) RP1059.

[5] N.S. Osborne. Bul. BS 9, 405 (1913) S197.

[6] International Critical Tables 3, 121 (1928).

Washington, November 11, 1937. 